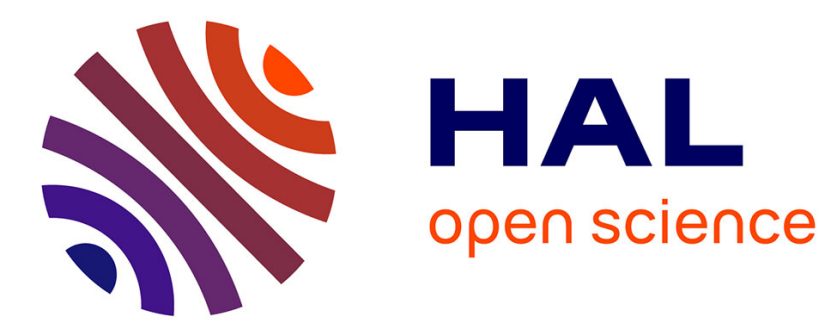

\title{
Characterization of dislocation interactions in olivine using electron tomography
}

\author{
Alexandre Mussi, Patrick Cordier, Sylvie Demouchy
}

\section{To cite this version:}

Alexandre Mussi, Patrick Cordier, Sylvie Demouchy. Characterization of dislocation interactions in olivine using electron tomography. Philosophical Magazine, 2015, Philosophical Magazine, 95 (4), pp.335-345. 10.1080/14786435.2014.1000996 . hal-01174166

\section{HAL Id: hal-01174166 https://hal.science/hal-01174166}

Submitted on 16 Jul 2019

HAL is a multi-disciplinary open access archive for the deposit and dissemination of scientific research documents, whether they are published or not. The documents may come from teaching and research institutions in France or abroad, or from public or private research centers.
L'archive ouverte pluridisciplinaire HAL, est destinée au dépôt et à la diffusion de documents scientifiques de niveau recherche, publiés ou non, émanant des établissements d'enseignement et de recherche français ou étrangers, des laboratoires publics ou privés. 


\title{
Characterization of dislocation interactions in olivine using electron tomography
}

\author{
Alexandre MUSSI ${ }^{1^{*}}$, Patrick CORDIER $^{1}$ and Sylvie DEMOUCHY ${ }^{2}$ \\ ${ }^{1}$ Unité Matériaux et Transformations, UMR 8207 CNRS-Université Lille1, \\ F-59655 Villeneuve d'Ascq, France \\ ${ }^{2}$ Géoscience Montpellier, UMR 5342 CNRS - Université Montpellier 2, \\ F-34095 Montpellier, France
}

Cite as:

$\begin{array}{lll}\begin{array}{l}\text { A. Mussi, P. Cordier \& S. Demouchy (2015) } \\ \text { using }\end{array} \text { electron } & \begin{array}{l}\text { Characterization of dislocation interactions in olivine } \\ \text { Magazine, }\end{array} \\ \text { Philosophical } & \text { M5), 335-345, }\end{array}$ https://doi.org/10.1080/14786435.2014.1000996

\begin{abstract}
We have investigated by electron tomography, in a transmission electronic microscope, the interactions between dislocations in olivine single crystals and polycrystals deformed in axial compression at $\mathrm{T}<1000{ }^{\circ} \mathrm{C}\left(\mathrm{T}<0.5 \mathrm{~T}_{\mathrm{m}}\right)$. Dislocations are mostly of the [001] type, except in the polycrystal where [100] and [001] dislocations have been activated. A few $\langle 101\rangle$ junctions have been found and characterized. Many collinear interactions have been identified either involving direct interactions between crossing dislocations of opposite Burgers vectors or indirect interactions between dislocations gliding in parallel planes and sessile dislocation loops. We suggest that collinear interaction, already identified as the primary source of strain hardening in FCC metals, is the main dislocation interaction mechanism in olivine deformed at temperatures below $1000^{\circ} \mathrm{C}$.
\end{abstract}

Keywords: Dislocation, junction, collinear interaction, TEM, electron tomography, olivine.

“Corresponding author: alexandre.mussi@univ-lille1.fr 


\section{Introduction}

Mantle convection, which drives plate tectonics, is needed to dissipate the internal heat of the Earth. This convection process within a solid mantle involves plastic deformations of rocks at a large scale. Olivine $(\mathrm{Mg}, \mathrm{Fe})_{2} \mathrm{SiO}_{4}$ is the main constituent of Earth's upper mantle, which extends down to $410 \mathrm{~km}$ of depth. Understanding plasticity in olivine is thus essential for studying the rheology of the upper mantle. Olivine has an orthorhombic symmetry with $a \approx 4.752 \AA, b \approx 10.193 \AA$ and $c \approx 5.977$ $\AA$ when described within the Pbnm space group [1]. Studies on plastic deformation of olivine and forsterite (the pure magnesium end-member) single and polycrystals were mostly conducted at high temperatures $\left(T>1000^{\circ} \mathrm{C} ; \mathrm{T}>0.5 \mathrm{~T}_{\mathrm{m}}\right)$ [2-9] and occasionally at lower temperatures [10-17]. Most studies focused on the slip system characterizations and have shown the occurrence of:

- dislocations with [100] and [001] Burgers vectors only (i.e., dislocations with [010] Burgers do not contribute to plastic deformation in olivine [18]);

- the (001), \{011\}, \{021\},\{031\} and (010) glide planes, for [100] dislocations, at high temperatures;

- the (100), (010) and \{110\} glide planes, for [001] dislocations, at high and low temperatures.

Until now, dislocation interactions have only been considered through numerical modelling [19]. As olivine has only two perpendicular slip directions ([100] and [001]), the formation of junctions is not favourable and dislocation storage is not anticipated. This is consistent with common observations of olivine deformed at high temperature where only low-angle subgrain boundaries are observed. Nevertheless, recent experiments performed at low temperature have shown numerous dislocation entanglements [16, 20].

In this study, the dislocation interactions in olivine are experimentally characterized by transmission electron microscopy (TEM) from samples previously used for the olivine rheology studies conducted by Demouchy et al. at low temperatures $[17,20]$. Electron tomography is used in this work to investigate threedimensional dislocation microstructures in order to understand dislocation interaction mechanisms. 


\section{Experimental details}

\subsection{Sample and deformation experiment}

Three specimens, all prepared from San Carlos olivine (Arizona, USA), were investigated:

- A polycrystal deformed at $900^{\circ} \mathrm{C}$, at a strain rate of $1.1 \times 10^{-5} \mathrm{~s}^{-1}$ (PoEM 22);

- A single crystal oriented to activate the [001](010) slip system and deformed at $850^{\circ} \mathrm{C}, 7.06 \times 10^{-6} \mathrm{~s}^{-1}$ (PoEM 11);

- A single crystal compressed at $806^{\circ} \mathrm{C}, 5.1 \times 10^{-5} \mathrm{~s}^{-1}$, and oriented to activate the [001](100), the [001](110) and the [100](001) slip systems (PoEM 9).

All samples were deformed in compression under a confining pressure of $300 \mathrm{MPa}$ of argon using a high-pressure high-temperature gas apparatus [17, 20, 21, 22] at Geosciences Montpellier (University of Montpellier 2). The olivine polycrystal has been produced from an olivine fine-grained powder sintered at a high temperature $\left(1250^{\circ} \mathrm{C}\right)$ during 3 hours under the same confining pressure conditions. The specimens are cylindrical: $9.45 \mathrm{~mm}$ in diameter and $20.03 \mathrm{~mm}$ long for PoEM 22; 4.2 $\mathrm{mm}$ in diameter and $6.61 \mathrm{~mm}$ long for PoEM 11; and $4.19 \mathrm{~mm}$ in diameter and 6.32 mm long for PoEM 9.

\subsection{Transmission electron tomography}

Sections cut from the three samples have been mechanically polished down to a thickness of ca. $30 \mu \mathrm{m}$. The resulting foils were Ar-ion sputtered with a Gatan ${ }^{\circledR}$ DuoMill TM model 600, to reach electron transparency. Then, thin carbon films were spread on the thin foils to insure electron conduction. TEM analyses were performed with a $\mathrm{FEI}^{\circledR}$ Tecnaï $\mathrm{G}^{2} 20$ Twin microscope, operating at $200 \mathrm{kV}$ with a $\mathrm{LaB}_{6}$ filament at the TEM facility at the University of Lille1. Dislocation microstructures were investigated in the weak-beam dark-field (WBDF) mode associated with a $0.1^{\circ}$ precession angle to weaken thickness fringes [23]. Nineteen tilted series were acquired every $2^{\circ}$ with an average tilt angle ranging from $-54^{\circ}$ to $50^{\circ}$. Most of them were acquired with WBDF conditions associated with precession (WBDF-P). The tilted series alignments were performed manually (a pixel precision could be achieved), as the contrasts of WBDF micrographs are too weak to allow automatic alignments. The contrast of the tilted series needed to be enhanced to optimize the quality of the reconstructed volume. Consequently, the micrographs have been filtered using a polynomial fit with the ImageJ software to improve contrast 
homogeneity of the background and of dislocations. Two reconstruction algorithms have been employed to generate the 3D images:

- The weighted back projection algorithm [24] used with the TomoJ plugin [25] accessible in ImageJ;

- The simultaneous iterative reconstruction technique algorithm [26] used with the Gatan ${ }^{\circledR} 3 D$ reconstruction software.

\section{Results}

A total of nineteen different areas have been analysed. Six of them come from PoEM 22, six from PoEM 11 and seven from PoEM 9. The analysed area sizes are ranging from 1.5 to $4.3 \mu \mathrm{m}$. The average dislocation density is approximately $1.7 \times 10^{13} \mathrm{~m}^{-2}$.

A typical microstructure observed in PoEM 11 is shown in Figure 1. All dislocations are in contrast with the 004 diffraction vector $(\boldsymbol{g})$ and out of contrast with g: $1 \overline{3} 0$ (figure 1). Consequently, PoEM 11 is exclusively composed of [001] dislocations. Similarly, using g: $22 \overline{2}$ and $\boldsymbol{g}$ : 062 , we verified that PoEM 9 is also exclusively composed of [001] dislocations. On the contrary, in PoEM 22, which is a polycrystal, both [100] and [001] dislocations are found with an approximate ratio 3:1 (see figure 8 in Demouchy et al. [20]).
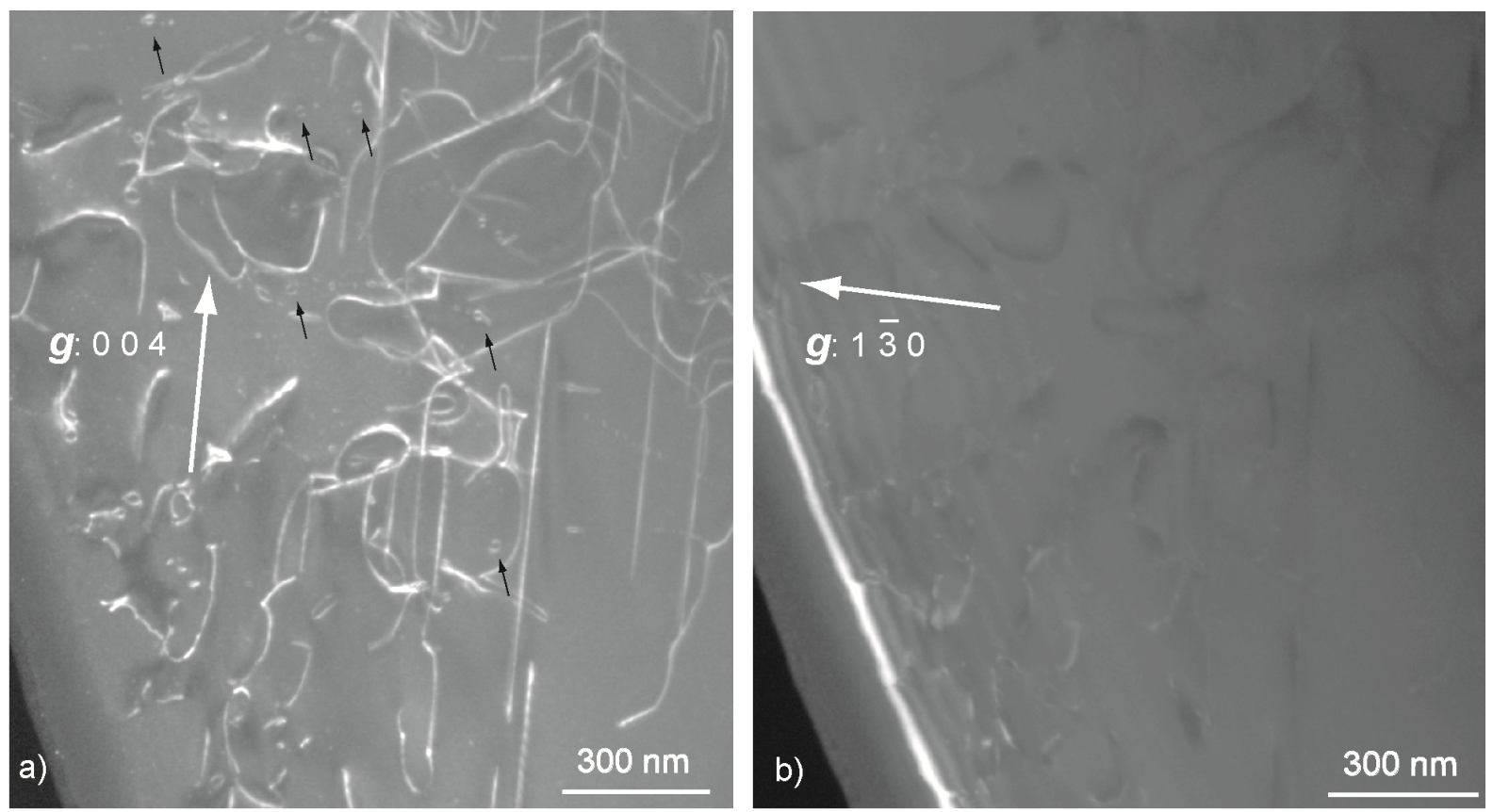

Figure 1: WBDF-P micrographs of [001] dislocations in POEM 11. Viewing direction near the [310] zone axis. (a) All the dislocations are in contrast with $\mathbf{g}$ : 004 (black arrows are pointing sessile dislocation loops). (b) All the dislocations are out of contrast with $\mathbf{g}: 1 \overline{3} 0$. 
As expected from previous studies, evidences for dislocation junctions are rare. However we have found some in PoEM 22. An example is shown on figure 2. Dislocations coloured in blue and the one in yellow are in contrast with $\boldsymbol{g}$ : 004 (figure 2(a)). But, all dislocations (blue, red and yellow) are in contrast with $\boldsymbol{g}: 2 \overline{2} 2$ (figure 2(b)). Consequently, blue dislocations are of the [001] type and red dislocations are of the [100] type. An electron tomography reconstruction volume (ETRV) of this zone, obtained with the $\boldsymbol{g}: 2 \overline{2} 2$, shows that the dislocation coloured in yellow is not the result, for a given orientation, of a superimposition of a blue and a red dislocation, but a distinct line attached to them. From the intensity profiles extracted from figure 2(b), we also note that the contrast of the yellow dislocation is significantly higher than the blue and the red ones (figure 2(c)). Since the contrast is linked to the $\boldsymbol{g} \cdot \boldsymbol{b}$ product (with $\boldsymbol{b}$ the Burgers vector) [27-28], we conclude that the Burgers vector of the yellow dislocation is [101]. As a result, the junction reaction is: $[100]+[001] \rightarrow[101]$.
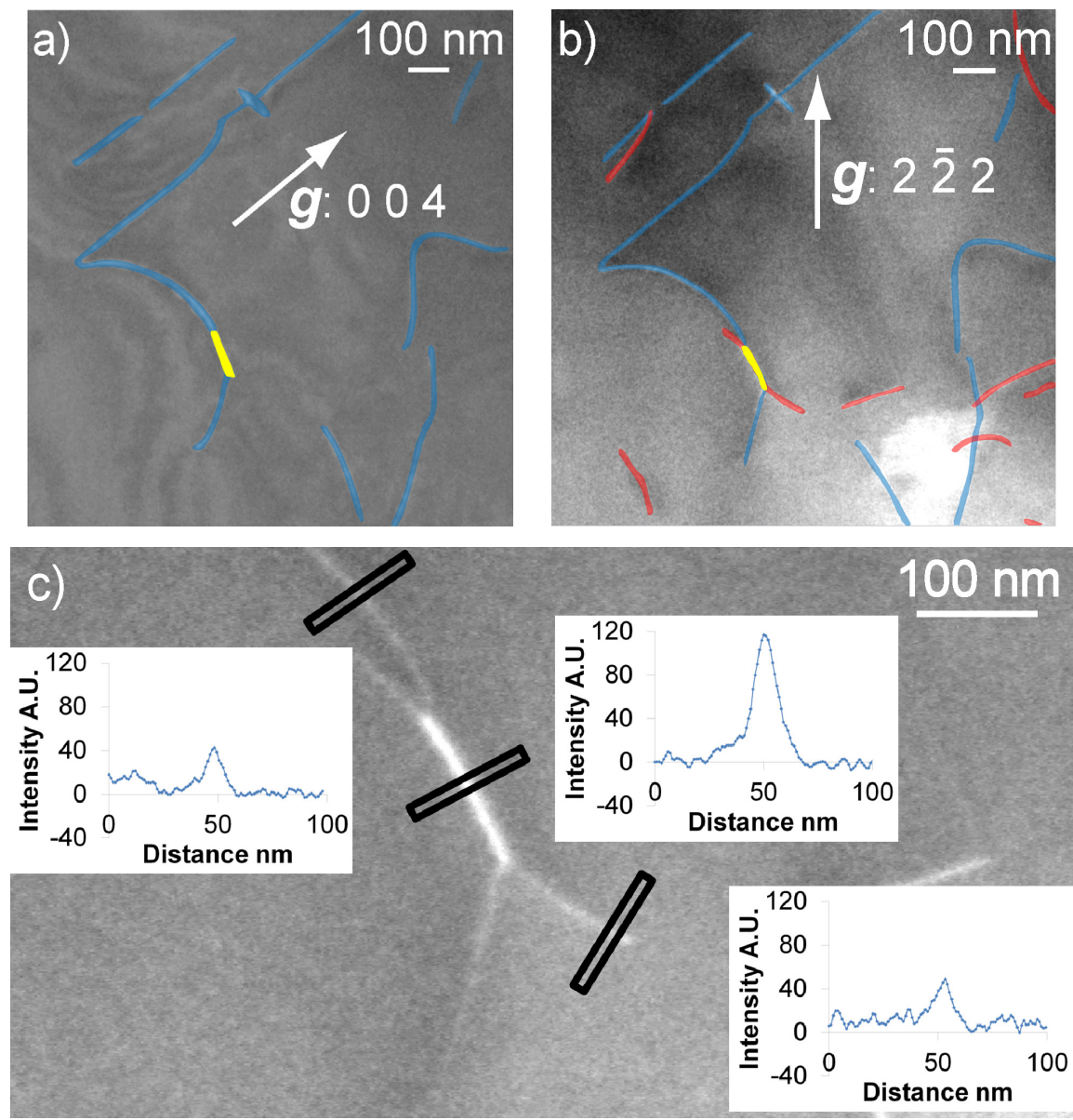

Figure 2: Micrograph in WBDF-P conditions of a $\langle 101\rangle$ junction in POEM 22. Viewing direction near the [110] zone axis. (a) The dislocations coloured in blue and the one in yellow are in contrast with $\mathbf{g}$ : 004 . (b) Blue, red and yellow dislocations are in contrast, with g: $2 \overline{2} 2$. (c) The intensity profiles, as inserts, across the blue, red and yellow dislocations with $\mathrm{g}: 2 \overline{2} 2$, show that the contrast of the yellow dislocation is significantly higher than the two other ones. 
A second zone from PoEM 22, where all dislocations are of [001] type (as they are in contrast with $\mathbf{g}$ : 004 ), is displayed in figure 3. We highlight three dislocations coloured in red, blue and green. The use of tomography enables us to find the glide planes of these dislocations by putting them edge on. The three long segments coloured in green glide in $(1 \overline{1} 0)$ (Figure $3(a))$. The blue dislocation glides in (140) (Figure 3c). The dislocation coloured in red glides in (010). Figure 3 shows that interaction with the blue dislocation leads to an annihilation of the green dislocation with a missing segment aligned parallel to [001]. Similarly, the red dislocation interacts with the green dislocation generating an annihilation segment also parallel to [001].
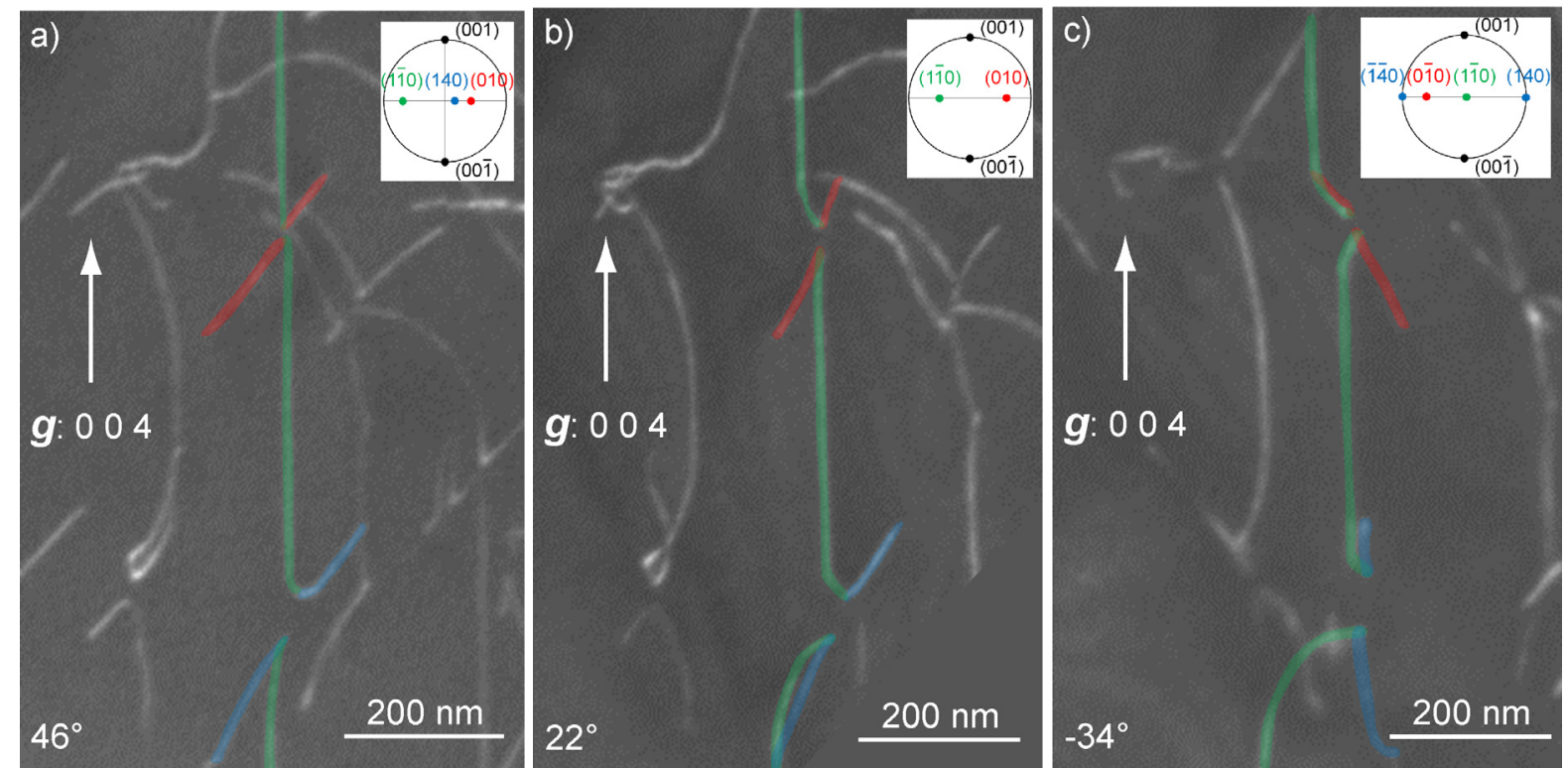

Figure 3: Collinear interactions in PoEM 22. WBDF-P micrographs, with g: 004 . Three orientations are presented corresponding to tilt angles of $46^{\circ}$ (a), $22^{\circ}$ (b) and $-34^{\circ}$ (c), with the corresponding stereographic projection on the top right hand corner. The ETRV, obtained with the 004 diffraction vector, enables us to find the glide planes of the dislocation coloured in green, in red and in blue. They are (1 10$),(010)$ and (140) respectively. (a) The dislocation coloured in green is almost parallel to [001] (the glide plane of this dislocation is nearly edge-on). (b) All the three glide planes are tilted. (c) The glide plane of the blue dislocation is practically edge-on, as this dislocation is seen almost vertical (i.e. along [001]) and as a straight line.

Other configurations suggesting dislocation annihilations by collinear interactions have been found. The WBDF-P micrographs presented in figure 4 are from PoEM 9. They show two half loops facing each other, observed with $\mathrm{g}: 22 \overline{2}$, tilted at $40^{\circ}$ (Figure $4 a$ ), at $4^{\circ}$ (Figure $\left.4(\mathrm{~b})\right)$ and $-34^{\circ}$ (Figure 4(c)). All dislocations involved are of the [001] type. The direction of the annihilated segment, which is indicated by a white dashed line, is not aligned with the screw direction: [001]. Electron tomography shows that those half loops are not glissile loops. They are each constituted of two 
segments, which glide in two parallel (100) planes (Figure 5(f)). Hence, the singular point where they meet (i.e., highlighted in green on figure $5(d)$ ) corresponds to the projection of a sessile segment connecting those two (100) planes (Figure 5(f)). This observation suggests that those two half loops correspond to an interaction process involving two [001] dislocations gliding on two parallel (100) planes.
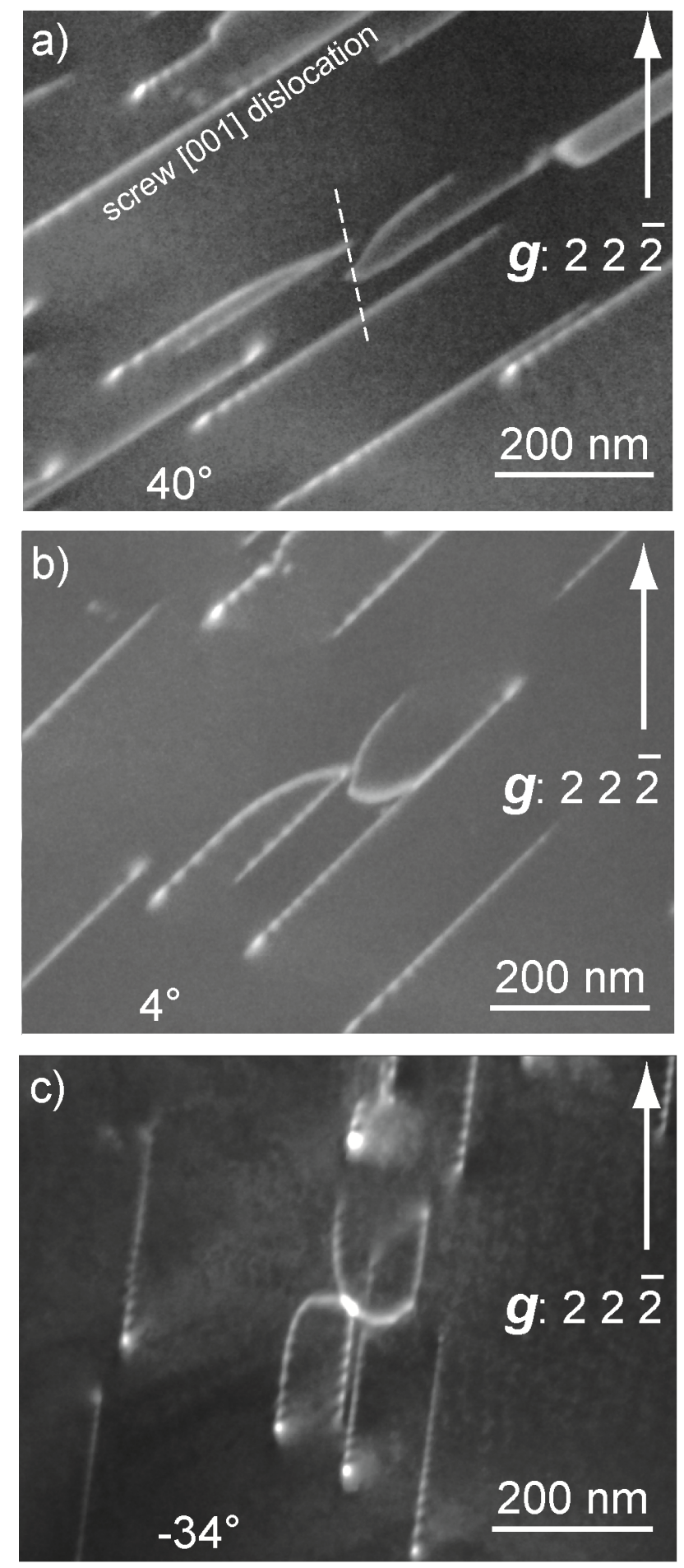

Figure 4: Dislocation interaction observation in POEM 9. (a) WBDF-P image, tilted at $40^{\circ}$, with g: $22 \overline{2}$, where two half-loops are facing each other. Identical WBDF-P images but tilted at $4^{\circ}(\mathrm{b})$ and identical WBDF-P images but $-34^{\circ}$ (c). 


\section{Discussion}

Electron tomography, which can reach angular resolution of $2^{\circ}$, is a powerful technique to characterize glide planes [20, 23, 29-37], cross-slip [23, 36], climb planes and dislocation interactions. In a previous study, we established that in olivine, [001] dislocations could glide in $\{120\}$ and $\{130\}$ [23]. We show in figure 3(c) that [001] dislocations can also glide in $\{140\}$.

We report here, to the best of our knowledge, the first unequivocal evidence of $\langle 101\rangle$ junctions in olivine. Durinck et al. [19] have considered theoretically the possibility of dislocation junctions in olivine and shown that the formation of $\langle 101\rangle$ junctions is very unlikely but not impossible. This is due to the fact that the [100] and [001] Burgers vectors are perpendicular. Under these conditions, the formation energy of a $\langle 101\rangle$ junction is approximately the same as the sum of the energies of the initial $[100]$ and [001] dislocation segments. We show here that in agreement with theoretical predictions, $\langle 101\rangle$ junctions can form. However they are rare, which also confirms theoretical predictions that their formation is energetically unfavourable and that they correspond to weak junctions.

Moreover, Durinck et al. (2007) have shown that annihilation of dislocations with collinear Burgers vectors is statistically the main interaction mechanism in olivine. This interaction mechanism called collinear interaction was discovered eleven years ago [19, 38-41]. Two dislocations with opposite signs and gliding in two different glide planes cross and interact. They create an annihilation junction, the direction of which is the intersection of the two glide planes. The annihilation junction creates two pinning points which impede dislocations and favor dislocation storage.. The collinear interaction has been shown to represent the primary source of strain hardening in FCC metals [38-40]. However, experimental evidences of collinear interactions are still rare [38, 42]. In this study, we have observed many occurrence of collinear interaction. One example is shown on figure 3. In this particular case, a long [001] dislocation segment (in green) gliding in $(1 \overline{1} 0)$ interacts with two [00 $\overline{1}]$ dislocations which glide in (010) (red) and in (140) (blue). As expected, annihilation takes place where the dislocations meet and their lines are interrupted. The missing segment is indeed aligned along the intersections of the glide planes: [001] (vertical on figure $3(\mathrm{~b}), 3(\mathrm{c}))$ as predicted. 
The configuration described in figure 4 and 5 is quite common in our olivine samples. Several lines of evidence suggest that it results also from an interaction. First, the half loops are not glissile. They connect lines which glide on two parallel (100) planes. Also the dislocations involved in this interaction are of opposite signs as indicated by the asymmetry of the contrasts, where the dislocations intersect the thin foil surfaces (see arrows on figure $5(d)$ ) as explained by the dynamical theory of diffraction [28]. These configurations cannot result from the standard collinear mechanism since they involve dislocations gliding on parallel planes. Indeed, the missing segment is not aligned along [001] as highlighted on figure 4(a). To account for this configuration, we propose that the dislocations have interacted with a small dislocation loop contained in a $\{h k l\}$ type plane. Indeed, there are pervasive occurrences in our samples, of interactions between dislocations and loops as shown on figure $5(\mathrm{~g})$. It can lead to a small annihilation as shown in figure 5(a). Since this interaction acts as a pinning point, it is possible that a second dislocation of opposite sign glides in the opposite direction on a parallel (100) plane and collides into this configuration. The possible result of the interaction is described on figure 5(b). The two lines of each half loop are connected by a short segment (in green) which is a remnant of the loop. However, when this short segment is viewed close to edge-on, it is almost invisible. Figure 5(c) presents a sketch of this dislocation configuration. This illustration corresponds to figure 5(d) (the small white arrows show that the two dislocations have opposite signs). The projection of the sketch along the [011] zone axis (Figure $5(\mathrm{e})$ ) shows that each dislocation segments of each half loop belong to two different (100) planes (edge-one with this orientation). The corresponding ETRV verifies this model (Figure 5(f)). It is only with a $92^{\circ}$ rotation, made possible by the electron tomography, that it can be evidenced. Further confirmation can be found on many equivalent configurations in the same sample. Figure $5(\mathrm{~g})$ shows one of them. It shows a [001] screw dislocation interacting with a sessile loop, which corresponds to the schematic illustration of figure 5(a) (we can note another sessile loop on the upper right hand corner of the micrograph). Furthermore, figure $5(\mathrm{~h})$ shows an interaction with a larger loop oriented in a different plane, which makes observation of the connecting segment easier. 

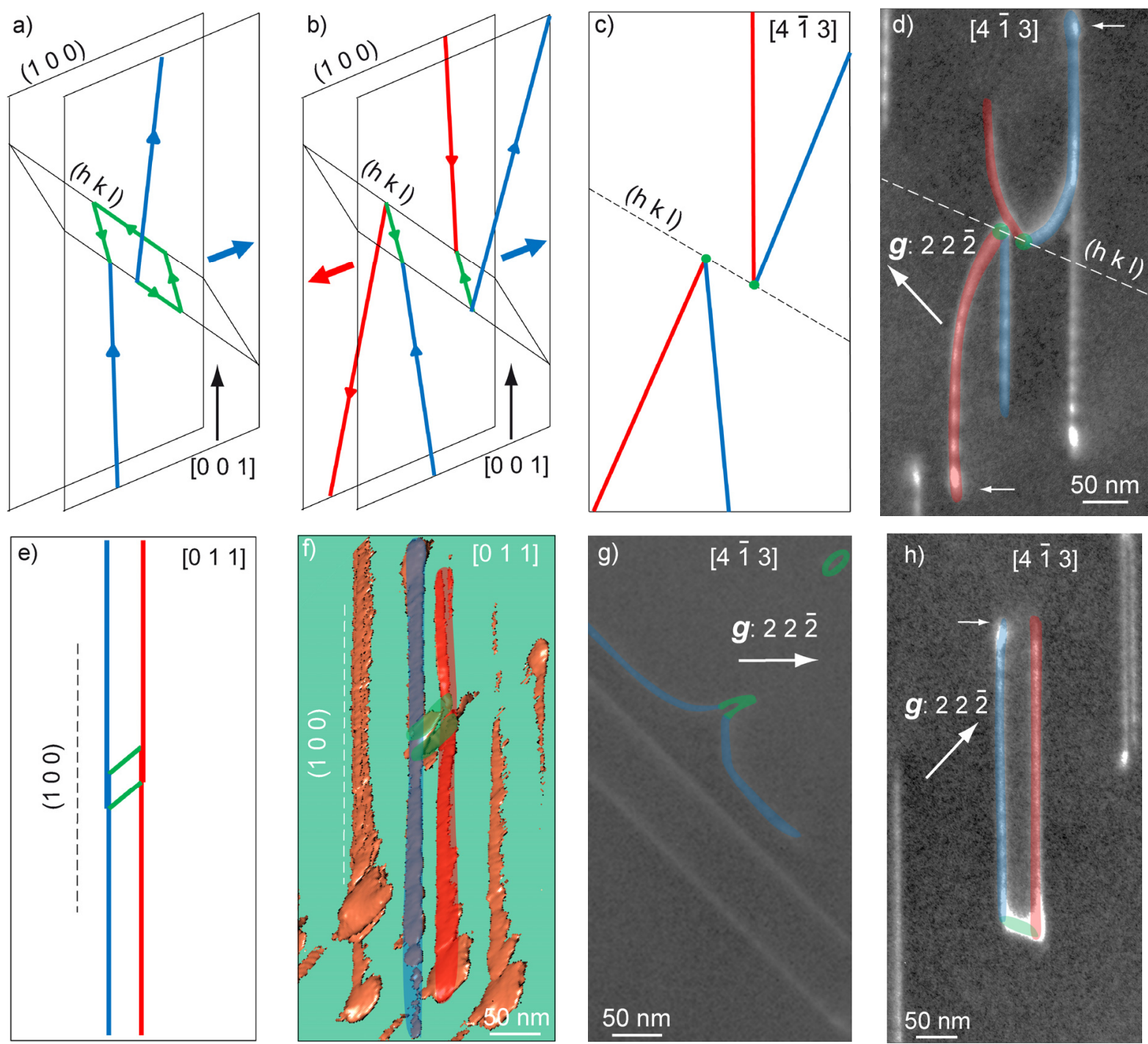

Figure 5: Mechanism proposed for the dislocation interaction shown in figure 4. (a) A [001] screw dislocation (in blue) glides on a (100) plane and interacts with a small sessile loop (in green), lying on a (hkl) plane, with an opposite Burgers vector, creating a small annihilation segment. (b) $A[00 \overline{1}]$ screw dislocation (in red) glides in the opposite direction on a parallel (100) plane and interacts with the loop, creating another small annihilation segment. (c) Projection of the schematic illustration model along the $[4 \overline{1} 3]$ zone axis with the $(\mathrm{hkl})$ plane edge-one. (d) Corresponding WBDF-P micrograph, obtained with g: $2 \overline{2} 2$. (e) Projection of the model along the [011] zone axis. (f) Corresponding ETRV, verifying that the (100) planes are edge-one. (g) Micrograph in WBDF-P conditions of the same sample, showing a [001] screw dislocation (in blue) interacting with a sessile loop (in green), corresponding to the schematic illustration of (a). (h) WBDF-P micrograph in the same sample, corresponding to the schematic illustrations of $(e)$ and $(f)$. 


\section{Conclusion and perspectives}

To summarize, we present here the dislocation interaction mechanisms observed in olivine single crystals and polycrystals deformed at temperature below $1000^{\circ} \mathrm{C}$.

When both [100] and [001] glides are activated simultaneously, reactions may take place leading to $\langle 101\rangle$ junctions. We provide here a characterization of such junctions. However, our observations are compatible with theoretical predictions that such events are not common and do not lead to strong junctions.

Yet, our observations point at collinear annihilation as the main interaction process in olivine. As proposed on FCC metals, we find pervasive evidence for collinear annihilations between dislocations gliding in intersecting planes. The fact that [001] dislocations tend to glide in many $\{h k 0\}$ planes enhances the probabilities of such interactions. The presence in our samples of many debris in the form of sessile [001] dislocation loops (see black arrows on figure 1(a)) is at the origin of another mechanism. This mechanism leads to collinear annihilation following the interaction with such loops of two dislocations gliding in parallel planes.

Altogether, our observations suggest that the collinear interaction, already identified as the main source for hardening in FCC metals, is also the main dislocation interaction mechanism in olivine deformed at temperature below $1000{ }^{\circ} \mathrm{C}$. This mechanism was already proposed theoretically by Durinck et al. [19]. It is now verified experimentally.

\section{Acknowledgements:}

The TEM national facility in Lille is supported by the CNRS (INSU) and the Conseil Régional du Nord Pas de Calais, France.

\section{References}

[1] R.M. Hazen, Am. Mineral. 61 (1976) p.1280.

[2] Q. Bai and D.L. Kohlstedt, Philos. Mag. A. 66 (1992) p.1149.

[3] M. Darot and Y. Gueguen, J. Geophys. Res. 86 (1981) p.6219.

[4] W.B. Durham and C. Goetze, J. Geophys. Res. 82 (1977) p.5737.

[5] W.B. Durham, C. Goetze and B. Blake, J. Geophys. Res. 82 (1977) p.5755.

[6] Y. Gueguen, Geophys. Res. Lett. 6 (1979) p.357. 
[7] Y Gueguen and M. Darot, Philos. Mag. A 45 (1982) p.419.

[8] O. Jaoul, M. Michaut, Y. Gueguen and D. Ricoult, Phys. Chem. Miner. 5 (1979) p.15.

[9] D.L. Kohlstedt and C. Goetze, J. Geophys. Res. 79 (1974) p.2045.

[10] C.B Raleigh, J. Geophys. Res. 73 (1968) p.5391.

[11] P. Phakey, G. Dollinger and J. Christie, Transmission electron microscopy of experimentally deformed olivine crystals, in Flow and Fracture of rocks, H.C. Heard, I.Y. Borg and N.L. Carter, eds., Am. Geophys. Un. Geophys. Monogr. Ser., AGU, Washington, 1972, p.117.

[12] B. Evans and C. Goetze, J. Geophys. Res. 84 (1979) p.5505.

[13] R.J. Gaboriaud, M. Darot, Y. Gueguen and J. Woirgard, Phys. Chem. Miner. 7 (1981) p.100.

[14] P. Raterron, Y. Wu, D.J. Weidner and J. Chen, Phys. Earth Planet. Inter. 145 (2004) p.149.

[15] S. Demouchy, S.E. Schneider, S.J. Mackwell, M.E. Zimmerman and D.L. Kohlstedt, Geophys. Res. Lett. 36 (2009) L04304.

[16] S. Demouchy, A. Mussi, F. Barou, A. Tommasi A and P. Cordier, AGU Fall meeting (2013) T43G-06.

[17] S. Demouchy, A. Tommasi, T.B. Ballaran and P. Cordier, Phys. Earth Planet. Inter. 220 (2013) p.37.

[18] K.Fujino, H. Nakazaki, H. Momoi, S.I. Karato, D.L. Kohlstedt, Phys. Earth Planet. Inter. 78 (1993) p.131.

[19] J. Durinck, B. Devincre, L. Kubin and P. Cordier, Am. Mineral. 92 (2007) p.1346.

[20] S. Demouchy, A. Mussi, F. Barou, A. Tommasi A and P. Cordier, Tectonophysics, 623 (2014) p.123.

[21] M.S. Paterson, Int. J. Rock Mech. Min. Sci. 7 (1970) p.512.

[22] M.S. Paterson, Rock deformation experimentation, in The brittle-ductile transition in rocks, A.G. Duba, W.B. Durham, J.W. Handin and H.F. Wang, eds., Geophys. Monogr. Ser., AGU, Washington, 1990, p.187.

[23] A. Mussi, P. Cordier, S. Demouchy and C. Vanmansart, Phys. Chem. Miner. 41 (2014) p.537.

[24] G.T. Herman, A.V. Lakshminarayanan and A. Naparstek, Comput. Biol. Med. (1976) p.259. 
[25] C. Messaoudi, T. Boudier, C.O. Sanchez Sorzano and S. Marco, TomoJ (tomography software for three-dimensional reconstruction in transmission electron microscopy); software available at http://u759.curie.fr/fr/download/softwares/TomoJ

[26] P. Penczek, M. Radermacher and J. Frank, Ultramicroscopy 40 (1992) p.33.

[27] R. Gevers, Philos. Mag. 7 (1962) p.59.

[28] D. B. Williams and C. B. Carter, in Transmission Electron Microscopy: A textbook for materials science (Plenum Press, 2nd edition, 2009).

[29] J.H. Sharp, J.S. Barnard, K. Kaneko, K. Higashida and P.A. Midgley, J. Phys. Conf. Ser. 126 (2008) 012013.

[30] M. Tanaka, K. Higashida, K. Kaneko, S. Hata and M. Mitsuhara, Scripta Mater. 59 (2008) p.901.

[31] M. Tanaka, M. Honda, M. Mitsuhara, S. Hata, K. Kaneko and K. Higashida, Mater. Trans. 49 (2008) p.1953.

[32] S. Hata, H. Miyazaki, S. Miyazaki, M. Mitsuhara, M. Tanaka, K. Kaneko, K. Higashida, K. Ikeda, H. Nakashima, S. Matsumara, J.S. Barnard, J.H. Sharp and P.A. Midgley, Ultramicroscopy 111 (2011) p.1168.

[33] J. Kacher and I.M. Robertson, Acta Mater. (2012) p.6657.

[34] J. Kacher, B.P. Efting, B. Cui and I.M. Robertson Curr. Opin. Solid State Mater. Sci. 18 (2014) p.227.

[35] J. Kacher and I.M. Robertson, Philos. Mag. 94 (2014) p.814.

[36] G.S. Liu, S.D. House, J. Kacher, M. Tanaka, K. Higashida and I.M. Robertson, Mater. Charact. 87 (2014) p.1.

[37] K. Misumi, K. Kaneko, T. Nishiyama, T. Maeda, K. Yamada, K.i. Ikeda, M. Kikuchi, K. Takata, M. Saga and K. Ushioda, J. Alloys Compd. 600 (2014) p.29.

[38] R. Madec, B. Devincre, L. Kubin, T. Hoc and D. Rodney, Science 301 (2003) p. 1879.

[39] L. Kubin, R. Madec and B. Devincre, MRS proceedings 779 (2003) W1.6.

[40] B. Devincre, T. Hoc and L. Kubin, Mater. Sci. Eng. A (2005) p.182.

[41] A. Alankar, I.N. Mastorakos, D.P. Field and H.M. Zbib, J. Eng. Mater. Technol. 134 (2012) 021018.

[42] E.A. Stach, R. Hull, R.M. Tromp, F.M. Ross, M.C. Reuter and J.C. Bean, Philos. Mag. A 80 (2000) p.2159. 
